Article

\title{
Immunogenicity of Varicella-Zoster Virus Glycoprotein E Formulated with Lipid Nanoparticles and Nucleic Immunostimulators in Mice
}

\author{
Han Cao ${ }^{\dagger}$, Yunfei Wang ${ }^{\dagger}$, Ning Luan and Cunbao Liu *(D) \\ Institute of Medical Biology, Chinese Academy of Medical Sciences and Peking Union Medical College, \\ Kunming 650118, China; caohan@imbcams.com.cn (H.C.); wangyf@imbcams.com.cn (Y.W.); \\ luanning@imbcams.com.cn (N.L.) \\ * Correspondence: cunbao_liu@163.com \\ + Authors contributed equally to this work.
}

Citation: Cao, H.; Wang, Y.; Luan, N.; Liu, C. Immunogenicity of

Varicella-Zoster Virus Glycoprotein E Formulated with Lipid Nanoparticles and Nucleic Immunostimulators in Mice. Vaccines 2021, 9, 310. https:// doi.org/10.3390/vaccines 9040310

Academic Editors: Heather L. Wilson, Azita Haddadi and George Mutwiri

Received: 15 February 2021

Accepted: 23 March 2021

Published: 25 March 2021

Publisher's Note: MDPI stays neutral with regard to jurisdictional claims in published maps and institutional affiliations.

Copyright: () 2021 by the authors. Licensee MDPI, Basel, Switzerland. This article is an open access article distributed under the terms and conditions of the Creative Commons Attribution (CC BY) license (https:// creativecommons.org/licenses/by/ $4.0 /)$.

\begin{abstract}
Theoretically, the subunit herpes zoster vaccine Shingrix ${ }^{\mathrm{TM}}$ could be used as a varicella vaccine that avoids the risk of developing shingles from vaccination, but bedside mixing strategies and the limited supply of the adjuvant component QS21 have made its application economically impracticable. With lipid nanoparticles (LNPs) that were approved by the FDA as vectors for severe acute respiratory syndrome coronavirus 2 vaccines, we designed a series of vaccines efficiently encapsulated with varicella-zoster virus glycoprotein E (VZV-gE) and nucleic acids including polyinosinic-polycytidylic acid (Poly I:C) and the natural phosphodiester CpG oligodeoxynucleotide (CpG ODN), which was approved by the FDA as an immunostimulator in a hepatitis $B$ vaccine. Preclinical trial in mice showed that these LNP vaccines could induce VZV-gE IgG titers more than 16 times those induced by an alum adjuvant, and immunized serum could block in vitro infection completely at a dilution of 1:80, which indicated potential as a varicella vaccine. The magnitude of the cell-mediated immunity induced was generally more than 10 times that induced by the alum adjuvant, indicating potential as a zoster vaccine. These results showed that immunostimulatory nucleic acids together with LNPs have promise as safe and economical varicella and zoster vaccine candidates.
\end{abstract}

Keywords: herpesvirus 3; human; varicella; chickenpox; herpes zoster; shingles; humoral immunity; cell-mediated immunity; nucleic acid immunostimulator; Poly I:C (polyinosinic-polycytidylic acid); CpG ODN (CpG oligodeoxynucleotide); lipid nanoparticle

\section{Introduction}

As its name indicates, varicella-zoster virus (VZV) causes two distinct diseases, i.e., varicella/chickenpox upon primary infection and zoster/shingles when latent viruses in the sensory ganglia reactivate [1]. In fact, nearly everyone comes in to contact with this virus before adulthood and shingles affects one in three people during their lifetime [2]. While attenuated strains (e.g., the Oka strain) have been used worldwide as varicella vaccines at a dose of 1000-10,000 plaque-forming units (PFU) since approval by the FDA in 1995, they may remain in the sensory ganglia and reactivate similar to the corresponding wild-type strains, causing herpes zoster in immunosenescent (e.g., older people) and immunocompromised populations (e.g., HIV carriers and cancer chemotherapy patients), which may result in postherpetic neuralgia that lasts for weeks to years without effective pain relievers available [3-9].

Cell-mediated immunity (CMI) rather than humoral immune responses has been indicated to play a key role in restricting latent VZV and preventing zoster [10-14]. On the basis of this information, the following two forms of zoster vaccines that boost preexisting cellular immune responses caused by primary exposure or varicella vaccination are available on the market: a single subcutaneous dose of an attenuated virus as high as 
20,000 PFU in ZOSTVAX ${ }^{\circledR}$ (developed in 2005 by Merk \& Co., Inc., Kenilworth, NJ, USA) or two intramuscular doses of the subunit vaccine Shingrix ${ }^{\mathrm{TM}}$ (developed in 2017 by Glaxo Smith Kline (GSK), Rockville, MD, USA) which contains the extracellular domain of VZV glycoprotein $\mathrm{E}(\mathrm{gE})$ and the AS01B adjuvant system. In addition to the strict conditions required for manufacturing and maintaining the necessary high titers of ZOSTVAX ${ }^{\circledR}$, the efficacy of this vaccine declines from $70 \%$ in people aged $50-59$ to less than $38 \%$ in people older than $70[15,16]$. In contrast, the protection rates of Shingrix ${ }^{\mathrm{TM}}$ are higher than $90 \%$ in all of the age groups tested, including people older than 80 , yet bedside mixing strategies and the limited supply of its adjuvant component QS21 have made Shingrix ${ }^{\mathrm{TM}}$ very expensive (approximately 150-200 USD per dose) [17-22].

In our previous reports, we proved that encapsulation of economical nucleic acid immunostimulators including polyinosinic-polycytidylic acid (Poly I:C) and the natural phosphodiester CpG oligodeoxynucleotide (CpG ODN) into poly(lactic-co-glycolic acid) (PLGA)-based nanoparticles showed excellent efficacy in therapeutic TC-1-grafted tumor models, in which CMI responses play decisive roles [23,24]. Although this economical adjuvant system also showed potential roles in VZV-gE CMI responses, the application of PLGA carriers is approved by the FDA for only chemical medicines, not vaccines. In addition, the encapsulation efficiency of nucleic acids by PLGA is less than $30 \%$ through the double-emulsion (w/ow) solvent evaporation method, which needs to be improved $[25,26]$.

Because of its high contagiousness, morbidity, and mortality characteristics, severe acute respiratory syndrome coronavirus 2 (SARS-CoV-2) has spread worldwide within months. Correspondingly, a new form of vaccine based on ionizable lipids, which were once designed as carriers for siRNA therapy for cancers, was adopted as an mRNA carrier and approved by the FDA within 1 year to prevent coronavirus disease 2019 (COVID-19) [27,28]. These lipid nanoparticles (LNPs) not only show good safety but also excellent nucleic acid encapsulation efficiency and potency to facilitate cellular uptake and endosomal escape, which are quite helpful in inducing antigen-specific CMI responses that play a key role in restricting latent VZV and preventing zoster, as mentioned above [29,30]. On the basis of this background information, we produced a series of potential subunit vaccines based on LNPs, tested the encapsulation efficiencies of VZV-gE and nucleic acid immunostimulators, and evaluated the immunogenicity of the vaccines in mice and their potency as VZV vaccines.

\section{Materials and Methods}

\subsection{Vaccines}

The compositions of the designed vaccines are shown in Table 1.

LNP vaccines were prepared using a modified procedure previously described for mRNA vaccines [31-33]. Briefly, lipids (from AVT Pharmaceutical Technology Co., Ltd., Shanghai, China) were dissolved in ethanol at molar ratios of 50:10:37.5:2.5 (MC3/DSPC/ cholesterol/DMG-PEG2000). The lipid mixtures were combined with $100 \mathrm{mM}$ citrate buffer ( $\mathrm{pH} 4.0)$ containing the extracellular domain of $\mathrm{gE}$ expressed in Chinese hamster ovary cells (supplied by AtaGenix Laboratory Co., Ltd., Wuhan, China), high-performance liquid chromatography-grade phosphodiester CpG ODN including BW006 (5'-tcg acg ttc gtc gtt cgt cgt tc- $3^{\prime}$ ) and 2395 (5'-tcg tcg ttt tcg gcg c:gc gcc g-3') (supplied by Sangon Biotech Co., Ltd., Shanghai, China), and low-molecular-weight Poly I:C (InvivoGen, Inc. San Diego, CA, USA) at a ratio of 3:1 with a microfluidic mixer (Precision Nanosystems, Inc., Vancouver, BC, Canada). Formulations were dialyzed against PBS, concentrated with a centrifugal filtration tube (Millipore), passed through a $0.22 \mu \mathrm{m}$ syringe filter (PALL), and stored at $4{ }^{\circ} \mathrm{C}$ until use. Particle sizes were tested with a Zetasizer Nano ZS particle size analyzer (Malvern Panalytical, Malvern, UK). Loaded gE was detected with a bicinchoninic acid protein assay kit (Beyotime, Shanghai, China) and encapsulation efficiency was calculated as the amount of loaded $\mathrm{gE}$ detected as compared with the initial amount of gE input in citrate buffer. Loaded nucleic acids were detected with the Quant-iT OliGreen ssDNA Reagent Kit (Thermo Fisher, Eugene, OR, USA) and encapsulation efficiency was calculated 
as the amount of loaded nucleic acids detected as compared with the amount of initial nucleic acids input in citrate buffer.

Table 1. Designed vaccine composition of each dose.

\begin{tabular}{ccccc}
\hline \multirow{2}{*}{ Vaccine Group } & \multirow{2}{*}{ gE $(\mu \mathrm{g})$} & \multicolumn{2}{c}{ CpG $(\mu \mathrm{g})$} & \multirow{2}{*}{ Poly I:C $(\mu \mathrm{g})$} \\
\cline { 3 - 4 } & & BW006 & $\mathbf{2 3 9 5}$ & \\
Blank & & & & \\
LNP & 10 & & & \\
Alum+gE & 10 & & & \\
LNP-gE & 10 & 12.5 & & \\
LNP-BW006-gE & 10 & & 12.5 & \multirow{2}{*}{12.5} \\
LNP-2395-gE & 10 & & & \\
LNP-PolyI:C-gE & 10 & 6.25 & 6.25 & \multirow{2}{*}{3.125} \\
LNP-BW006+2395-gE & 10 & 3.125 & 3.125 & \\
LNP-BW006+2395+PolyI:C-gE & & & & \\
\hline
\end{tabular}

\subsection{Preclinical Trial in Mice}

Six-week-old female specific pathogen-free (SPF) C57BL/6N mice (15-18 g) were supplied by Vital River Laboratory Animal Technology Ltd. (Beijing, China), randomly divided into 9 groups with 6 mice in each group $(N=6)$, maintained under SPF conditions and housed with free access to food and water at the Central Animal Services of the Institute of Medical Biology, Chinese Academy of Medical Sciences and Peking Union Medical College (IMB, CAMS). The mice were immunized intramuscularly in the thigh muscle three times with $50 \mu \mathrm{L}$ of immunogen at 2-week intervals. Blood samples (via cardiac puncture) and spleens were collected 2 weeks after the final immunization. After clotting at $4{ }^{\circ} \mathrm{C}$ overnight, serum was collected after centrifugation at $3500 \mathrm{rpm}$ for $20 \mathrm{~min}$.

\subsection{Enzyme-Linked Immunosorbent Assay (ELISA) for gE-Specific Antibodies}

$\mathrm{gE}(2 \mu \mathrm{g} / \mathrm{mL})$ was used to coat 96 -well plates (Corning) at $4{ }^{\circ} \mathrm{C}$ overnight. After blocking with $5 \%(w / v)$ skim milk at $37^{\circ} \mathrm{C}$ for $1 \mathrm{~h}$, the plates were incubated with serial dilutions of mouse sera at $37^{\circ} \mathrm{C}$ for $1 \mathrm{~h}$. Bound antibodies were detected with goat anti-mouse IgG-horseradish peroxidase (HRP) conjugate (1:5000, Bio-Rad, Hercules, CA, USA) as a secondary antibody. Ten minutes after the addition of the substrate $3,3^{\prime}, 5,5^{\prime}-$ tetramethylbenzidine (BD), $1 \mathrm{~mol} / \mathrm{L}$ phosphoric acid was added to terminate the reaction. The absorbance at $450 \mathrm{~nm}$ was detected with a spectrophotometer (BioTek Instruments, Inc., Winooski, VT, USA). IgG titers were defined as end-point dilutions showing cutoff signals above OD450 = 0.1, and IgG titers lower than 100 were defined as 100 for calculations.

\subsection{Fluorescence-Based Plaque Reduction Neutralization Assay}

Live attenuated VZV (Changchun BCHT Biotechnology Co., Ltd., Changchun, China) was incubated with mouse sera at given dilutions at $37^{\circ} \mathrm{C}$ for $1 \mathrm{~h}$ and added to monolayer MRC- 5 cells (human fetal lung fibroblasts, Conservation Genetics CAS Kunming Cell Bank, Kunming, China) in 96-well plates (Corning) for $1 \mathrm{~h}$, and then the plates were washed with Dulbecco's modified Eagle's medium (DMEM, Thermo Fisher). The cells were incubated with DMEM without fetal bovine serum (FBS) for $16 \mathrm{~h}$ at $37{ }^{\circ} \mathrm{C}$ in $5 \% \mathrm{CO}_{2}$. After washing with PBS, the plates were fixed with precooled $80 \%(v / v)$ acetone at $-20{ }^{\circ} \mathrm{C}$ for $10 \mathrm{~min}$ and blocked with $2 \%(w / v)$ skim milk at $37^{\circ} \mathrm{C}$ for $1 \mathrm{~h}$. After washing 3 times with PBS, in-house rabbit anti-VZV antiserum (1:250) was added and incubated at $37^{\circ} \mathrm{C}$ for $1 \mathrm{~h}$. The bound antibodies were detected with fluorescein isothiocyanate (FITC)-labeled goat anti-rabbit IgG antibodies (1:100, Cayman Chemical Company, Ann Arbor, MI, USA) at $37^{\circ} \mathrm{C}$ for $1 \mathrm{~h}$. Plates were imaged with a Cytation 1 imaging reader (BioTek Instruments, Inc., Winooski, VT, USA) [34]. 


\subsection{Enzyme-Linked Immunospot (ELISPOT) Assay}

Spleens were dispersed with a $70 \mu \mathrm{m}$ cell strainer (NEST, Wuxi, China). After red blood cell lysis with ammonium chloride potassium buffer, splenocytes were collected by centrifugation at $1800 \mathrm{rpm}$ for $5 \mathrm{~min}$, the number of cells was calculated, and the cells were suspended in Roswell Park Memorial Institute (RPMI, Thermo Fisher) 1640 medium supplemented with 10\% $(v / v)$ FBS (Biological Industries, Cromwell, CT, USA) and penicillinstreptomycin (Thermo Fisher) at a final concentration of $3 \times 10^{6}$ cells $/ \mathrm{mL}$. Then, $100 \mu \mathrm{L}$ of cells were added to each well of a 96-well plate (Corning Inc., Corning, NY, USA) for further analysis with an ELISPOT assay kit (BD), according to the manufacturer's protocol. $\mathrm{gE}$ and pooled peptides (purity $\geq 95 \%$, synthesized by GL Biochem Co., Ltd. Shanghai, China) at $10 \mu \mathrm{g} / \mathrm{mL}$ were both selected to stimulate gE-specific $\mathrm{T}$ cell responses by incubation of cells with protein/peptides overnight. Spots were counted with an ELISPOT reader system (Autoimmun Diagnostika GmbH, Strassberg, Germany) after immunoimaging [26].

\subsection{Statistical Analysis}

gE concentrations and encapsulation efficiency were compared with an unpaired t-test. Nucleic acid concentrations, encapsulation efficiency, IgG titers, and ELISPOT numbers were compared using one-way analysis of variance (ANOVA) followed by Dunnett's multiple comparisons test with the LNP-BW006+2395-gE group as the control. Diameters and polydispersity index (PDI) results were compared using one-way ANOVA followed by Tukey's multiple comparisons test (GraphPad Prism 7.0 software, GraphPad Software Inc., La Jolla, CA, USA) $\left({ }^{*} p<0.05 ;{ }^{* *} p<0.01 ;{ }^{* * *} p<0.001 ;{ }^{* * * *} p<0.0001\right.$; ns, no significant difference).

\section{Results}

\subsection{LNPs Efficiently Encapsulated gE and Nucleic Acid Immunostimulators}

As shown in Table 1, $10 \mu \mathrm{g} \mathrm{gE}$ were designed for each dose of vaccine. When $300 \mu \mathrm{g} \mathrm{gE}$ was added to $1.5 \mathrm{~mL}$ citrate buffer as the raw materials for 20 doses of LNP vaccines, the encapsulation efficiency was nearly 100\% (group LNP-gE in Table 2 and Figure 1A,B), which is $50 \%$ more than we expected. Coencapsulation of nucleic acid immunostimulators showed limited interference with the gE loading efficiency except for in the LNP-BW006+2395+Poly I:C-gE group (85\% in Figure 1B), which had the lowest total nucleic acid input among all of the groups (Table 1), implying that nucleic acid characteristics instead of nucleic acid loading limits may influence the loading efficiency of gE in LNPs.

Table 2. Vaccine compositions of 20 doses.

\begin{tabular}{|c|c|c|c|c|}
\hline \multirow{2}{*}{ Vaccine Group } & \multirow{2}{*}{$\mathrm{gE}(\mu \mathrm{g})$} & \multicolumn{2}{|c|}{ CpG ( $(\mu g)$} & \multirow{2}{*}{ Poly I:C ( $\mu \mathrm{g}$} \\
\hline & & BW006 & 2395 & \\
\hline \multicolumn{5}{|l|}{$\begin{array}{l}\text { Blank } \\
\text { LNP }\end{array}$} \\
\hline Alum $+\mathrm{gE}$ & 200.00 & & & \\
\hline LNP-gE & 299.72 & & & \\
\hline LNP-BW006-gE & 276.09 & 229.83 & & \\
\hline LNP-2395-gE & 274.73 & & 297.02 & \\
\hline LNP-PolyI:C-gE & 273.37 & & & 139.52 \\
\hline LNP-BW006+2395-gE & 270.65 & 149.89 & 149.89 & \\
\hline LNP-BW006+2395+PolyI:C-gE & 250.39 & 45.23 & 45.23 & 45.23 \\
\hline
\end{tabular}


A

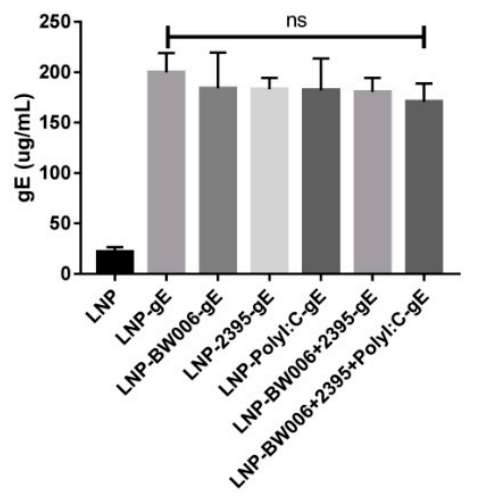

C

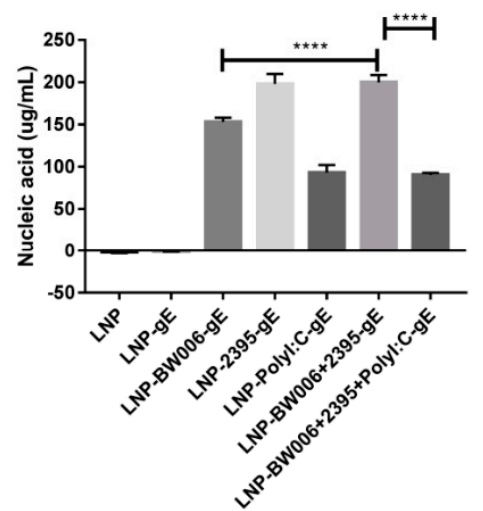

E

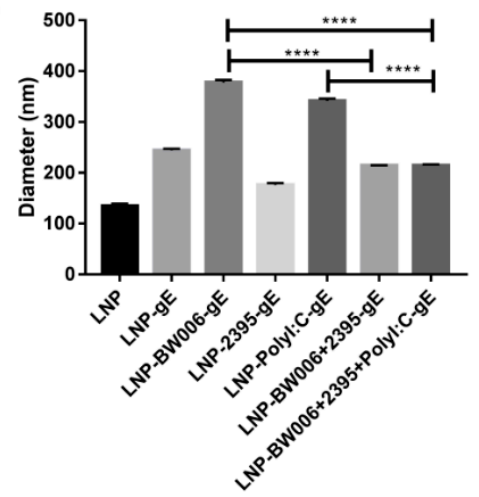

B

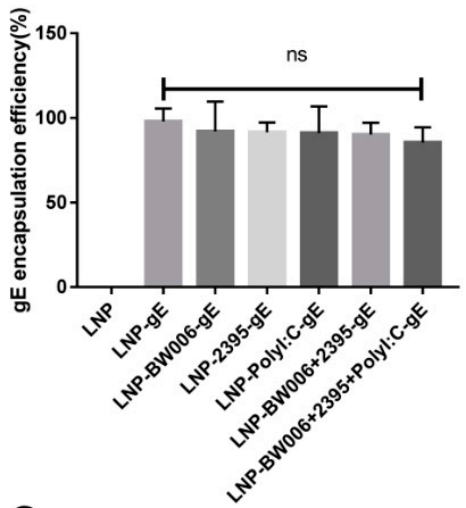

D

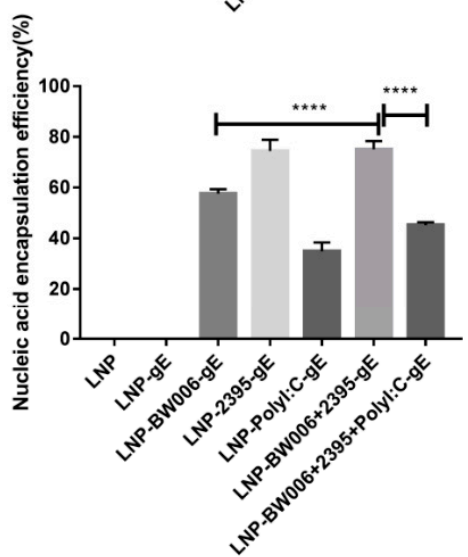

$\mathbf{F}$

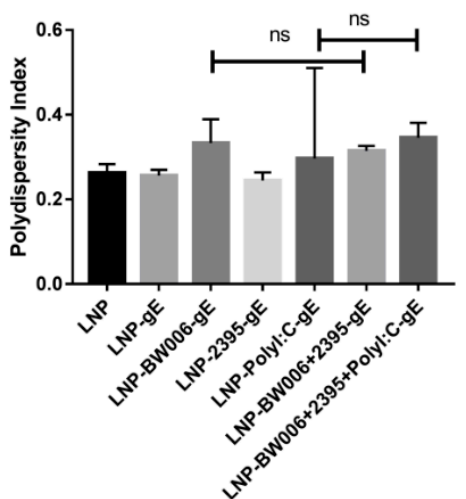

Figure 1. Characterization of LNP vaccines. (A) gE concentration; (B) gE encapsulation efficiency; (C) Nucleic acid immunostimulator concentration; (D) Nucleic acid immunostimulator encapsulation efficiency; (E) Diameters tested by a size analyzer; (F) Polydispersity index of LNPs. ${ }^{* * * *} p<0.0001$. ns, no significant difference.

According to our previous experiences on the potency of nucleic acids to stimulate adaptive immune responses and the nucleic acid loading efficiency of ionizable lipids, up to $12.5 \mu \mathrm{g}$ nucleic acids were designed for each dose of vaccine (Table 1) [24,35]. When $400 \mu \mathrm{g}$ nucleic acid immunostimulators were added to $1.5 \mathrm{~mL}$ citrate buffer with $300 \mu \mathrm{g} g \mathrm{~g}$ as the raw materials for 20 doses of LNP vaccines, the encapsulation efficiency varied (Table 2 and Figure 1C,D). While CpG ODN 2395 alone (vaccine LNP-2395-gE) showed an encapsulation efficiency of 74.4\%, CpG ODN BW006 alone (vaccine LNP-BW006-gE) showed a lower encapsulation efficiency of 57.6\%, and Poly I:C alone (vaccine LNP-Poly I:C-gE) showed the lowest encapsulation efficiency of $35 \%$, which is lower than the mRNA encapsulation efficiency reported (69-100\%) [35]. Interestingly, CpG ODN 2395 seemed to be helpful for elevating the encapsulation efficiency of CPG ODN BW006, as the coencapsulation 
efficiency of CpG ODN 2395 and CpG ODN BW006 (vaccine LNP-BW006+2395-gE) was $75.1 \%$, which was much higher $(p<0.0001)$ than the encapsulation efficiency of CpG ODN BW006 alone (vaccine LNP-BW006-gE, 57.6\%). This ability seemed to be weakened by the presence of Poly I:C, as the encapsulation efficiency of the LNP-BW006+2395+Poly I:C-gE group was only $45.2 \%$. Because the total nucleic acid input was $375 \mu \mathrm{g}$ instead of $400 \mu \mathrm{g}$ in this group, we also attributed this decreased loading efficiency to nucleic acid characteristics instead of nucleic acid loading limits, similar to the conclusion for $\mathrm{gE}$.

While CpG ODN 2395 condensed the diameters of LNPs (214.4 nm for LNP-BW006 +2395-gE versus $377.7 \mathrm{~nm}$ for LNP-BW006-gE, $214.2 \mathrm{~nm}$ for LNP-BW006+2395+Poly I:C-gE versus $341.6 \mathrm{~nm}$ for LNP-Poly I:C-gE and $377.7 \mathrm{~nm}$ for LNP-BW006-gE) (Figure 1E) and showed some tendency toward uniform LNPs (LNP-BW006+2395-gE versus LNP-BW006gE, LNP-BW006+2395+Poly I:C-gE versus LNP-Poly I:C-gE) (Figure 1F), only the polydispersity index (PDI, a measure of the heterogeneity of a sample based on size) showed a slight reverse tendency with nucleic acid immunostimulator encapsulation efficiencies.

\subsection{LNP-Encapsulated gE and Nucleic Acid Immunostimulators Induced Potent Humoral Immune Responses}

LNPs with encapsulated $\mathrm{gE}$ alone (LNP-gE) induced six times more gE-specific IgG antibodies than the alum adjuvant (24,000 versus 4000, Figure 2A). Coencapsulation of nucleic acid immunostimulators by LNPs further elevated gE-specific IgG antibody levels (all above 64,000). Among the immunostimulators, CpG ODN 2395 seemed to be less potent than CpG ODN BW006 in inducing humoral responses considering its higher encapsulation efficiency (64,000 IgG titers and 74.4\% encapsulation for LNP-2395-gE versus 96,000 IgG titers and 57.6\% encapsulation for LNP-BW006-gE). Poly I:C should be the most potent immunostimulator for inducing humoral responses because its encapsulation rate in LNP-Poly I:C-gE was approximately 60\% of that of CpG ODN W006 in LNP-BW006-gE, yet they induced the same IgG titers (96,000 for both). This potency was confirmed in the LNP-BW006+2395+Poly I:C-gE group, which contained the lowest amount of nucleic acid immunostimulators but induced the highest IgG tiers $(128,000)$, which could be defined as synergistic effects [23]. Interestingly, this phenomenon was also observed between CpG ODN BW006 and CpG ODN 2395, which induced higher IgG titers $(128,000$ for LNP-BW006+2395-gE) than CpG ODN BW006 alone at the same concentration $(96,000$ for LNP-BW006-gE).

The IgG1-to-IgG2a titer ratio was calculated to evaluate the Th1-Th1 balance, with the Th1 responses standing for more potent cellular mediated immunity that was better suited to control latent VZV [36,37]. While all of the immunogens containing gE induced obvious IgG1 subtype antibodies (Figure 2B), only LNPs with nucleic acid immunostimulators induced obvious IgG2a subtype antibodies (Figure 2C). Among these LNP formulations, LNP-Poly I:C-gE induced much higher IgG1 antibody titers with an IgG1-to-IgG2a ratio of 16, which indicated a Th2-dominant humoral immune response similar to that induced by the alum adjuvant and LNP alone (Figure 2D) [37-39]. Correspondingly, the presence of CpG ODNs was accompanied by more balanced Th1-Th2 responses, and coencapsulation of CpG ODN BW006 and 2395 (LNP-BW006+2395-gE) showed more Th1-biased potency, which was indicated by the fact that the IgG1-to-IgG2a ratio in this group was the only one with a value less than 1 . Notably, coencapsulation of CpG ODNs could balance the powerful Th2-dominant humoral immune response induced by Poly I:C, which showed an IgG1-to-IgG2a ratio of 1 instead of 16, i.e., the ratio for Poly I:C alone.

A representative image of a VZV neutralization assay is shown in Figure 2E. At a dilution of 1:80, immunized serum from the LNP-BW006+2395-gE group blocked nearly all infection of MRC- 5 cells by live attenuated VZV strains, which showed the potency of these LNP vaccines as varicella vaccines. 
A

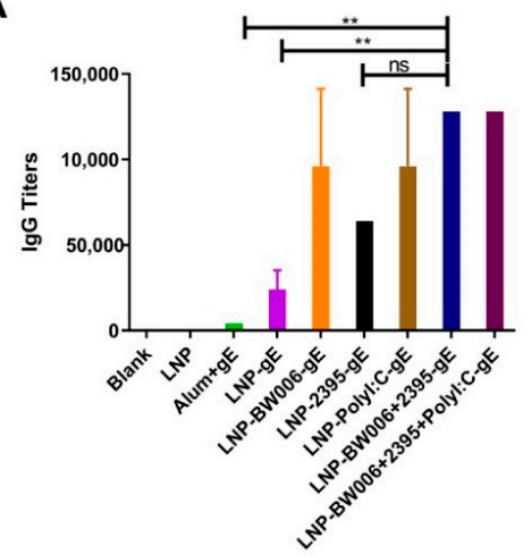

C

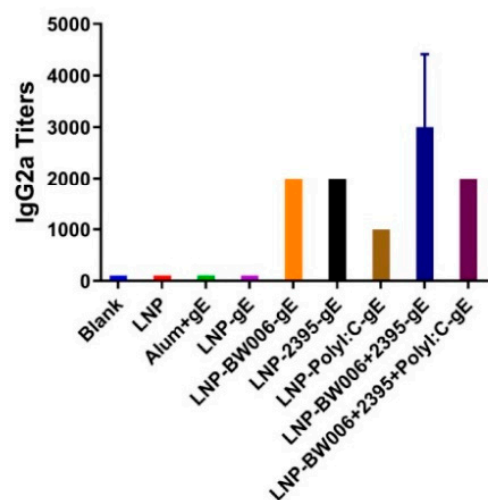

E

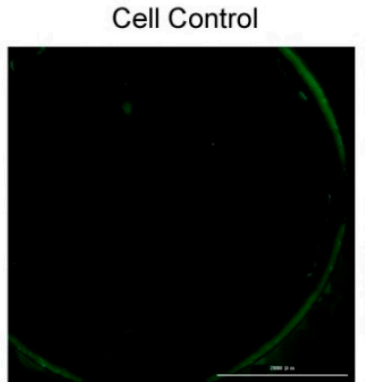

B

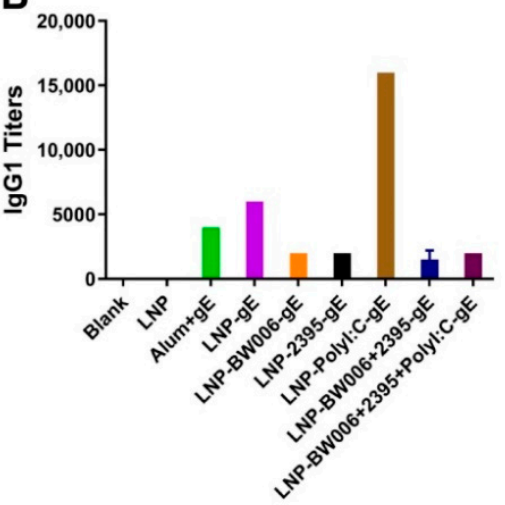

D

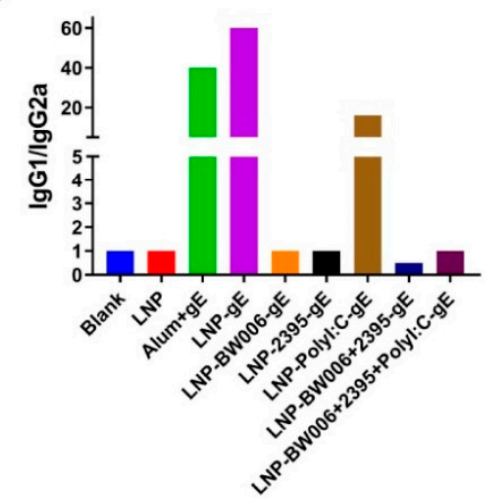

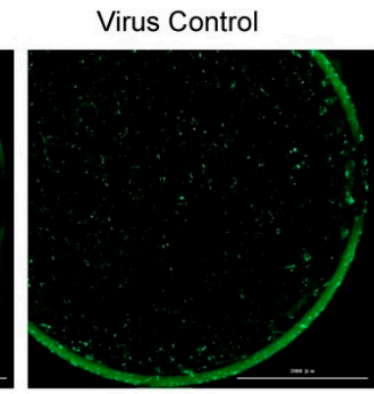

Serum dilution 1:80

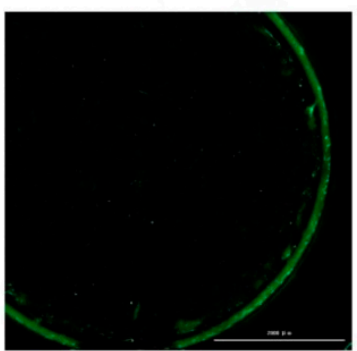

Figure 2. Humoral immune responses. (A) gE-specific IgG titers; (B) gE-specific IgG1 titers; (C) gEspecific IgG2a titers; (D) IgG1/IgG2a ratios; (E) Neutralizing effects of serum from LNP-BW006+2395gE-immunized mice. Scale bar, $2000 \mu \mathrm{m} .{ }^{* *} p<0.01$. ns, no significant difference.

\subsection{LNP-Encapsulated gE and Nucleic Acid Immunostimulators Induced Potent CMI}

To verify the CMI responses indirectly suggested by the IgG1-to-IgG2a ratios in Figure 2D, gE-specific IFN- $\gamma$ - and IL-2-producing splenocytes were detected by ELISPOT. In each group of mice immunized with the same vaccine, incubation of splenocytes with either protein $\mathrm{gE}$ (Figure 3A) or peptides from $\mathrm{gE}$ (Figure $3 \mathrm{~B}$ ) at the concentration of $10 \mu \mathrm{g} / \mathrm{mL}$ both showed similar tendency of IFN- $\gamma$-producing cells as compared with other groups. At the same time, $\mathrm{gE}$ are more potent than the peptide pools we selected for stimulation, which showed as higher numbers of IFN- $\gamma$-producing cells as compared with peptides stimulated mice immunized with the same vaccine formulations. Notably, while CpG ODN BW006 was more potent in inducing humoral immune responses than CpG ODN 2395 (LNP-BW006-gE versus LNP-2395-gE in Figure 2A), it showed similar or lower potency in inducing IFN- $\gamma$-producing splenocytes than LNP-2395-gE (Figure 3A,B), even when its lower encapsulation efficiency was considered (57.6\% for LNP-BW006-gE 
and 74.4\% for LNP-2395-gE in Figure 1D). In contrast to CpG ODN BW006, Poly I:C showed higher potency in inducing not only humoral immune responses (LNP-Poly I:C-gE in Figure 2A) but also IFN- $\gamma$-producing splenocytes (LNP-Poly I:C-gE in Figure 3A,B), especially when its lower encapsulation efficiency was considered (35\% for LNP-Poly I:C-gE in Figure 1D). Synergistic effects on the stimulation of IFN- $\gamma$-producing splenocytes were detected between CpG ODN BW006 and 2395 (LNP-BW006+2395-gE versus LNP-BW006$\mathrm{gE}$ and LNP-2395-gE in Figure 3A,B), considering the lower potency of IFN- $\gamma$-producing splenocyte induction by CpG ODN BW006. These synergistic effects were also identified between CpG ODN BW006, CpG ODN 2395, and Poly I:C in LNP-BW006+2395+Poly I:C$\mathrm{gE}$ considering their lower coencapsulation efficiencies, as we concluded for the humoral immune response.

A

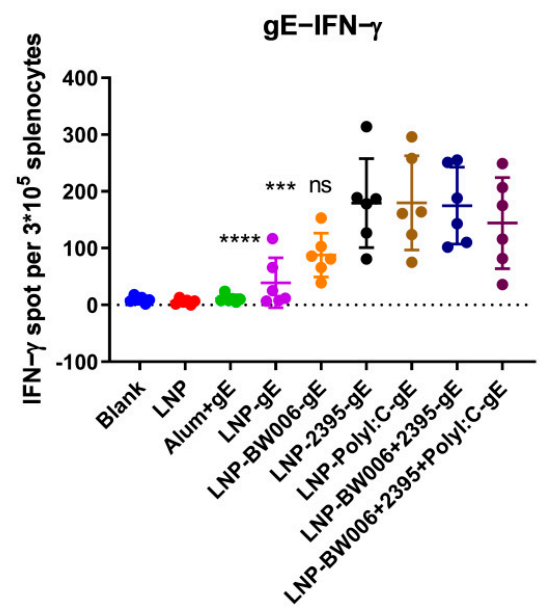

C

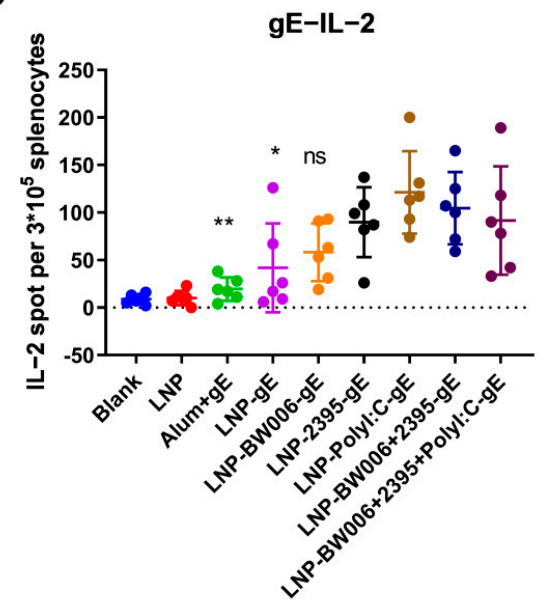

B

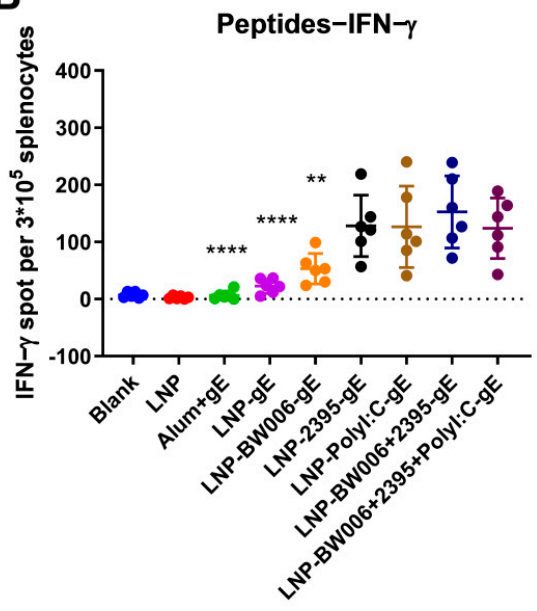

D

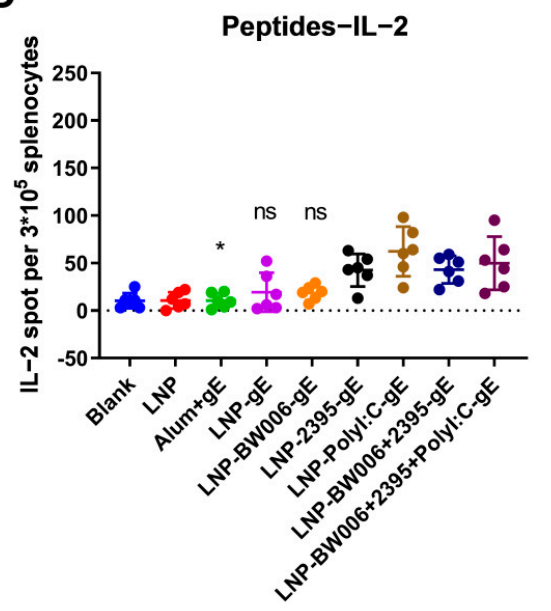

Figure 3. Enzyme-linked immunospot (ELISPOT) assay performed with splenocytes. (A) IFN- $\gamma$ producing splenocytes after gE stimulation; (B) IFN- $\gamma$-producing splenocytes after pooled peptide stimulation; (C) IL-2-producing splenocytes after gE stimulation; (D) IL-2-producing splenocytes after pooled peptide stimulation. ${ }^{*} p<0.05,{ }^{* *} p<0.01,{ }^{* * *} p<0.001,{ }^{* * * *} p<0.0001$. ns, no significant difference. ELISPOT numbers were compared using one-way analysis of variance (ANOVA) followed by Dunnett's multiple comparisons test with the LNP-BW006+2395-gE group used as the control.

The above patterns were also observed for the stimulation of IL-2-producing splenocytes, as shown in Figure 3C,D. Compared with LNP vaccines with encapsulated nucleic acid immunostimulators, LNP vaccines alone (LNP-gE) and the alum adjuvant in- 
duced very low CMI according to our ELISPOT analyses of both IFN- $\gamma$ and IL-2, which suggested the potency of LNP-encapsulated gE and nucleic acid immunostimulators as zoster vaccines.

\section{Discussion}

Because of the highly contagious character of VZV, nearly everyone comes into contact with this virus before adulthood. Live attenuated vaccines (e.g., the Oka strain) have been used worldwide to prevent primary infection, which causes varicella/chickenpox. Unfortunately, the live attenuated strain used in vaccines may lurk in the sensory ganglia and reactive as shingles/zoster similar to wild-type strains $[2,4,5]$. Subunit vaccines may be chosen as substitutes for the live attenuated varicella vaccines to prevent both chickenpox and the risk of shingles that comes from vaccination. The gE protein is a conserved glycoprotein essential for the replication and transmission of VZV [40-42]. The potential neutralization and $\mathrm{T}$ cell epitopes of $\mathrm{gE}$ make it an ideal target as a subunit vaccine antigen; however, its immunogenicity should be further strengthened by appropriate adjuvants $[40,41,43,44]$. Fortunately, $g E$ was efficiently loaded into LNPs that were developed for use as nucleic acid medicine/vaccine vectors (Figure 1A,B). When coencapsulated with nucleic acid immunostimulators in LNPs, gE induced specific IgG titers that were more than 16 times those induced by the alum adjuvant. Serum from immunized mice with an average IgG titer of 64,000 could completely block infection with the Oka VZV strain in vitro at a dilution of 1:80 (Figure 2E), which indicated promise as a safe varicella vaccine.

For zoster vaccines, CMI instead of humoral immune responses plays a key role in restricting latent VZV, which is vital for zoster vaccine efficacy [11]. Though live attenuated VZV (i.e., ZOSTVAX ${ }^{\circledR}$ ) can boost existing CMI to a certain extent, the difficulties related to virus purification, strict conditions required during transportation, and rapidly declining protective rate in people older than 70 still need to be solved. On the basis of $\mathrm{gE}$ and the novel adjuvant system AS01B, Shingrix ${ }^{\mathrm{TM}}$ has produced approximately 10 times stronger gE-specific CMI than ZOSTVAX ${ }^{\circledR}$, which is consistent with the higher protection rate of Shingrix ${ }^{\mathrm{TM}}$, especially in people older than 70 or 80 [36]. Unfortunately, one of the key components of the adjuvant AS01B (i.e., QS21) is a polysaccharide mixture that cannot be synthesized; it can only be extracted from the bark of Quillaja saponaria [45]. The limited distributions of $Q$. saponaria around the globe and strict quality control during the extraction processes of QS21 have made ShingrixT ${ }^{\mathrm{M}}$ very expensive (approximately 150-200 USD per dose).

With LNP-encapsulated gE and nucleic acid immunostimulators including Poly I:C and the natural phosphodiester CpG ODN, which can both be produced economically on a large scale, ELISPOT studies have shown that LNP vaccines, except for LNP-BW006$\mathrm{gE}$, all induced CMI responses above 10 times stronger than those induced by the alum adjuvant (Figure 3). According to a flow cytometry analysis reported in preclinical studies of Shingrix ${ }^{\mathrm{TM}}$ performed with mice, AS01B can induce seven-fold increases in CMI specific for $\mathrm{gE}$ as compared with an alum adjuvant [46]. According to previous studies on the CMI response based on gE and adjuvant systems including CIA09A, gE-specific ELISPOT tests correlate well with gE-specific cytokine-producing CD4+ and CD8+ T cell frequencies, although Th1 CD4+ cells are adopted more frequently than CD8+ T cells as good indicators for the evaluation of zoster vaccines in animal and clinical experiments [26,47]. The aforementioned CMI effects induced by both AS01B and CIA09A to target gE were tested in VZV-primed animal models, while our tests did not adopt this model due to the lack of highquality Oka strain-based vaccines with high titers, such as Varilrix from GSK and Zostavax from Merck. In fact, no pathological animal models are available for zoster vaccine studies, which may be partly attributed to the special skin structure of humans as compared with that of existing experimental animals, including mice and nonhuman primates. Primed VZV will neither become latent nor reactivate in mice, although replication may be probable according to reports on the detection of viral DNA 1 month after inoculation [48,49]. Compared with two intramuscular doses of the subunit vaccine or mRNA vaccine after 
VZV priming, the first dose of our three intramuscular injections might cause a comparably lower base level of VZV-specific immunity, but the effective induction of CMI by these LNP vaccines implied comparable or perhaps better potency than that observed in VZV-primed models, though a parallel study with the same immunization procedure should reflect these CMI responses more directly, and we will compare efficacies once these other formulations, such as Shingrix ${ }^{\mathrm{TM}}$, are available [2,46].

Considering their low encapsulation efficiency and strong but Th-2-balanced induced immune responses, adjuvant formulations without Poly I:C should be tested further (Figure 2D). In fact, synergistic effects on humoral responses and CMI that were comparable to those induced with Poly I:C were achieved when CpG ODN BW006 (class B CpG ODNs that are helpful to enhance humoral immunity) and CpG 2395 (class C CpG ODNs that are helpful to enhance both humoral immunity and cellular immunity) were coencapsulated (i.e., LNP-BW006+2395-gE), with a higher encapsulation efficiency (75\%), more condensed size (diameter $=214.4 \mathrm{~nm}$ ), and more uniform shapes $(\mathrm{PDI}=0.3)[50,51]$. In addition, while CpG ODN was approved in 2017 by the FDA as an adjuvant for the human hepatitis B virus vaccine HEPLISAV-B ${ }^{\mathrm{TM}}$ (Dynavax, Emeryville, CA, USA), Poly I:C has been used only as an antiviral medication in China, and the only clinical trial evaluating its application in vaccines by the FDA involves it as an adjuvant for rabies vaccines, which recently completed phase II clinical trial testing [52,53].

While the physical characteristics (including diameters and PDI) and components (including gE and nucleic acid contents) were stable when stored at $4{ }^{\circ} \mathrm{C}$ during our study, which is a priority compared with LNP-based mRNA vaccines designed for VZV that are stable at $-20{ }^{\circ} \mathrm{C}$ at present, longer stability at $4{ }^{\circ} \mathrm{C}$ still needs to be tested [2]. Interestingly, while aggregates formed during both the freeze-thaw cycles and the lyophilizationreconstitution process of LNP-based siRNA vaccines, the addition of lyoprotectants such as sucrose or trehalose maintained the physical characteristics, including the diameter and PDI [54]. Considering the stability of CPG ODNs as compared with that of siRNA and mRNA, we will test the stability and immunogenicity of our lyophilized LNPs during the lyophilization-reconstitution process and storage at $4{ }^{\circ} \mathrm{C}$, which may be a priority, as compared with the current unlyophilizable liposome-based adjuvant system (AS01B) for VZV subunit vaccines.

\section{Conclusions}

Overall, LNPs designed for siRNA/mRNA vaccines could efficiently encapsulate $\mathrm{gE}$ and nucleic acid immunostimulators, especially CpG ODNs. All of the components, except for Poly I:C (which could be removed), have been approved by the FDA as vaccine components and have shown good safety. These LNP vaccines could induce VZV-gE-specific humoral responses, showing great prospects as varicella vaccines without a potential risk of zoster, and they exhibit potential as zoster vaccines at much lower costs than current vaccines. Theoretically, successful application of these potential LNP-based varicella vaccines may exempt zoster vaccines in the future. In addition, the antigen-specific Th- 1 oriented immunogenicity induced by the LNP systems that, described in this study, might highly impact on subunit vaccine developments currently depends on alum adjuvants.

Author Contributions: Conceptualization, C.L.; methodology, H.C. and Y.W.; validation, Y.W.; formal analysis, C.L.; investigation, H.C., Y.W. and N.L.; writing-original draft preparation, C.L.; writing-review and editing, C.L.; project administration, C.L.; funding acquisition, C.L. All authors have read and agreed to the published version of the manuscript.

Funding: This research was financially funded by the CAMS Initiative for Innovative Medicine (grant number 2017-I2M-3-022), the Major Science and Technology Special Projects of Yunnan Province (grant number 202002AA100009), the Basic Research Projects of Yunnan Province, and the Funds for the Training of High-level Health Technical Personnel in Yunnan Province, China (grant number H-2019063). 
Institutional Review Board Statement: Animal experiments were approved by the Ethics Committee of Animal Care and Welfare of the Institute of Medical Biology, Chinese Academy of Medical Sciences and Peking Union Medical College (IMB, CAMS) (permit number SYXK (dian) K2019-00023), in accordance with the animal ethics guideline of the Chinese National Health and Medical Research Council and the Office of Laboratory Animal Management of Yunnan Province, China. All efforts were made to minimize animal suffering.

Conflicts of Interest: The authors declare no conflict of interest.

\section{References}

1. Zerboni, L.; Sen, N.; Oliver, S.L.; Arvin, A.M. Molecular mechanisms of varicella zoster virus pathogenesis. Nat. Rev. Microbiol. 2014, 12, 197-210. [CrossRef]

2. Monslow, M.A.; Elbashir, S.; Sullivan, N.L.; Thiriot, D.S.; Ahl, P.; Smith, J.; Miller, E.; Cook, J.; Cosmi, S.; Thoryk, E.; et al. Immunogenicity generated by mRNA vaccine encoding VZV gE antigen is comparable to adjuvanted subunit vaccine and better than live attenuated vaccine in nonhuman primates. Vaccine 2020, 38, 5793-5802. [CrossRef] [PubMed]

3. Arruti, M.; Pineiro, L.D.; Salicio, Y.; Cilla, G.; Goenaga, M.A.; Lopez de Munain, A. Incidence of varicella zoster virus infections of the central nervous system in the elderly: A large tertiary hospital-based series (2007-2014). J. Neurovirol. 2017, 23, 451-459. [CrossRef] [PubMed]

4. Breuer, J. Molecular Genetic Insights Into Varicella Zoster Virus (VZV), the vOka Vaccine Strain, and the Pathogenesis of Latency and Reactivation. J. Infect. Dis. 2018, 218, S75-S80. [CrossRef] [PubMed]

5. Garnett, G.P.; Grenfell, B.T. The epidemiology of varicella-zoster virus infections: The influence of varicella on the prevalence of herpes zoster. Epidemiol. Infect. 1992, 108, 513-528. [CrossRef]

6. Krause, P.R.; Klinman, D.M. Varicella vaccination: Evidence for frequent reactivation of the vaccine strain in healthy children. Nat. Med. 2000, 6, 451-454. [CrossRef] [PubMed]

7. Levin, M.J.; Bresnitz, E.; Popmihajlov, Z.; Weinberg, A.; Liaw, K.L.; Willis, E.; Curtis, J.R. Studies with herpes zoster vaccines in immune compromised patients. Expert. Rev. Vaccines 2017, 16, 1217-1230. [CrossRef]

8. Moodley, A.; Swanson, J.; Grose, C.; Bonthius, D.J. Severe Herpes Zoster Following Varicella Vaccination in Immunocompetent Young Children. J. Child Neurol. 2019. [CrossRef]

9. Uebe, B.; Sauerbrei, A.; Burdach, S.; Horneff, G. Herpes zoster by reactivated vaccine varicella zoster virus in a healthy child. Eur. J. Pediatr. 2002, 161, 442-444. [CrossRef]

10. Asada, H. VZV-specific cell-mediated immunity, but not humoral immunity, correlates inversely with the incidence of herpes zoster and the severity of skin symptoms and zoster-associated pain: The SHEZ study. Vaccine 2019, 37, 6776-6781. [CrossRef]

11. Gilbert, P.B.; Gabriel, E.E.; Miao, X.; Li, X.; Su, S.C.; Parrino, J.; Chan, I.S. Fold rise in antibody titers by measured by glycoproteinbased enzyme-linked immunosorbent assay is an excellent correlate of protection for a herpes zoster vaccine, demonstrated via the vaccine efficacy curve. J. Infect. Dis. 2014, 210, 1573-1581. [CrossRef] [PubMed]

12. Haberthur, K.; Engelmann, F.; Park, B.; Barron, A.; Legasse, A.; Dewane, J.; Fischer, M.; Kerns, A.; Brown, M.; Messaoudi, I. CD4 T cell immunity is critical for the control of simian varicella virus infection in a nonhuman primate model of VZV infection. PLoS Pathog. 2011, 7, e1002367. [CrossRef]

13. Steain, M.; Sutherland, J.P.; Rodriguez, M.; Cunningham, A.L.; Slobedman, B.; Abendroth, A. Analysis of T cell responses during active varicella-zoster virus reactivation in human ganglia. J. Virol. 2014, 88, 2704-2716. [CrossRef]

14. Weinberg, A.; Levin, M.J. VZV T cell-mediated immunity. Curr. Top. Microbiol. Immunol. 2010, 342, 341-357. [CrossRef]

15. Gilderman, L.I.; Lawless, J.F.; Nolen, T.M.; Sterling, T.; Rutledge, R.Z.; Fernsler, D.A.; Azrolan, N.; Sutradhar, S.C.; Wang, W.W.; Chan, I.S.; et al. A double-blind, randomized, controlled, multicenter safety and immunogenicity study of a refrigerator-stable formulation of Zostavax. Clin. Vaccine Immunol. 2008, 15, 314-319. [CrossRef]

16. Oxman, M.N.; Levin, M.J.; Johnson, G.R.; Schmader, K.E.; Straus, S.E.; Gelb, L.D.; Arbeit, R.D.; Simberkoff, M.S.; Gershon, A.A.; Davis, L.E.; et al. A vaccine to prevent herpes zoster and postherpetic neuralgia in older adults. N. Engl. J. Med. 2005, 352, 2271-2284. [CrossRef]

17. Chlibek, R.; Bayas, J.M.; Collins, H.; de la Pinta, M.L.; Ledent, E.; Mols, J.F.; Heineman, T.C. Safety and immunogenicity of an AS01-adjuvanted varicella-zoster virus subunit candidate vaccine against herpes zoster in adults $>=50$ years of age. J. Infect. Dis. 2013, 208, 1953-1961. [CrossRef] [PubMed]

18. Cohen, J.I. A new vaccine to prevent herpes zoster. N. Engl. J. Med. 2015, 372, 2149-2150. [CrossRef]

19. Cunningham, A.L.; Heineman, T.C.; Lal, H.; Godeaux, O.; Chlibek, R.; Hwang, S.J.; McElhaney, J.E.; Vesikari, T.; Andrews, C.; Choi, W.S.; et al. Immune Responses to a Recombinant Glycoprotein E Herpes Zoster Vaccine in Adults Aged 50 Years or Older. J. Infect. Dis. 2018, 217, 1750-1760. [CrossRef] [PubMed]

20. Cunningham, A.L.; Lal, H.; Kovac, M.; Chlibek, R.; Hwang, S.J.; Diez-Domingo, J.; Godeaux, O.; Levin, M.J.; McElhaney, J.E.; Puig-Barbera, J.; et al. Efficacy of the Herpes Zoster Subunit Vaccine in Adults 70 Years of Age or Older. N. Engl. J. Med. 2016, 375, 1019-1032. [CrossRef] [PubMed]

21. Haumont, M.; Jacquet, A.; Massaer, M.; Deleersnyder, V.; Mazzu, P.; Bollen, A.; Jacobs, P. Purification, characterization and immunogenicity of recombinant varicella-zoster virus glycoprotein gE secreted by Chinese hamster ovary cells. Virus Res. 1996, 40, 199-204. [CrossRef] 
22. Leroux-Roels, I.; Leroux-Roels, G.; Clement, F.; Vandepapeliere, P.; Vassilev, V.; Ledent, E.; Heineman, T.C. A phase 1/2 clinical trial evaluating safety and immunogenicity of a varicella zoster glycoprotein e subunit vaccine candidate in young and older adults. J. Infect. Dis. 2012, 206, 1280-1290. [CrossRef] [PubMed]

23. Liu, C.; Chu, X.; Sun, P.; Feng, X.; Huang, W.; Liu, H.; Ma, Y. Synergy effects of Polyinosinic-polycytidylic acid, CpG oligodeoxynucleotide, and cationic peptides to adjuvant HPV E7 epitope vaccine through preventive and therapeutic immunization in a TC-1 grafted mouse model. Hum. Vaccin. Immunother. 2018, 14, 931-940. [CrossRef] [PubMed]

24. Liu, C.; Chu, X.; Yan, M.; Qi, J.; Liu, H.; Gao, F.; Gao, R.; Ma, G.; Ma, Y. Encapsulation of Poly I:C and the natural phosphodiester CpG ODN enhanced the efficacy of a hyaluronic acid-modified cationic lipid-PLGA hybrid nanoparticle vaccine in TC-1-grafted tumors. Int. J. Pharm. 2018, 553, 327-337. [CrossRef]

25. Iqbal, M.; Zafar, N.; Fessi, H.; Elaissari, A. Double emulsion solvent evaporation techniques used for drug encapsulation. Int. J. Pharm. 2015, 496, 173-190. [CrossRef]

26. Wang, Y.; Qi, J.; Cao, H.; Liu, C. Immune Responses to Varicella-Zoster Virus Glycoprotein E Formulated with Poly(Lactic-coGlycolic Acid) Nanoparticles and Nucleic Acid Adjuvants in Mice. Virol. Sin. 2020. [CrossRef] [PubMed]

27. Anderson, E.J.; Rouphael, N.G.; Widge, A.T.; Jackson, L.A.; Roberts, P.C.; Makhene, M.; Chappell, J.D.; Denison, M.R.; Stevens, L.J.; Pruijssers, A.J.; et al. Safety and Immunogenicity of SARS-CoV-2 mRNA-1273 Vaccine in Older Adults. N. Engl. J. Med. 2020, 383, 2427-2438. [CrossRef]

28. Polack, F.P.; Thomas, S.J.; Kitchin, N.; Absalon, J.; Gurtman, A.; Lockhart, S.; Perez, J.L.; Perez Marc, G.; Moreira, E.D.; Zerbini, C.; et al. Safety and Efficacy of the BNT162b2 mRNA Covid-19 Vaccine. N. Engl. J. Med. 2020, 383, 2603-2615. [CrossRef] [PubMed]

29. Rietwyk, S.; Peer, D. Next-Generation Lipids in RNA Interference Therapeutics. ACS Nano 2017, 11, 7572-7586. [CrossRef]

30. Sergeeva, O.V.; Koteliansky, V.E.; Zatsepin, T.S. mRNA-Based Therapeutics-Advances and Perspectives. Biochemistry 2016, 81, 709-722. [CrossRef]

31. Bahl, K.; Senn, J.J.; Yuzhakov, O.; Bulychev, A.; Brito, L.A.; Hassett, K.J.; Laska, M.E.; Smith, M.; Almarsson, O.; Thompson, J.; et al. Preclinical and Clinical Demonstration of Immunogenicity by mRNA Vaccines against H10N8 and H7N9 Influenza Viruses. Mol. Ther. 2017, 25, 1316-1327. [CrossRef] [PubMed]

32. Richner, J.M.; Himansu, S.; Dowd, K.A.; Butler, S.L.; Salazar, V.; Fox, J.M.; Julander, J.G.; Tang, W.W.; Shresta, S.; Pierson, T.C.; et al. Modified mRNA Vaccines Protect against Zika Virus Infection. Cell 2017, 169, 176. [CrossRef] [PubMed]

33. Richner, J.M.; Jagger, B.W.; Shan, C.; Fontes, C.R.; Dowd, K.A.; Cao, B.; Himansu, S.; Caine, E.A.; Nunes, B.T.D.; Medeiros, D.B.A.; et al. Vaccine Mediated Protection Against Zika Virus-Induced Congenital Disease. Cell 2017, 170, 273-283.e12. [CrossRef]

34. Liu, C.; Huang, P.; Zhao, D.; Xia, M.; Zhong, W.; Jiang, X.; Tan, M. Effects of rotavirus NSP4 protein on the immune response and protection of the SR69A-VP8* nanoparticle rotavirus vaccine. Vaccine 2021, 39, 263-271. [CrossRef] [PubMed]

35. Hassett, K.J.; Benenato, K.E.; Jacquinet, E.; Lee, A.; Woods, A.; Yuzhakov, O.; Himansu, S.; Deterling, J.; Geilich, B.M.; Ketova, T.; et al. Optimization of Lipid Nanoparticles for Intramuscular Administration of mRNA Vaccines. Mol. Ther. Nucleic Acids 2019, 15, 1-11. [CrossRef]

36. Levin, M.J.; Kroehl, M.E.; Johnson, M.J.; Hammes, A.; Reinhold, D.; Lang, N.; Weinberg, A. Th1 memory differentiates recombinant from live herpes zoster vaccines. J. Clin. Investig. 2018, 128, 4429-4440. [CrossRef]

37. Wang, Y.; Wang, L.; Cao, H.; Liu, C. SARS-CoV-2 S1 is superior to the RBD as a COVID-19 subunit vaccine antigen. J. Med. Virol. 2021, 93, 892-898. [CrossRef] [PubMed]

38. Lefeber, D.J.; Benaissa-Trouw, B.; Vliegenthart, J.F.; Kamerling, J.P.; Jansen, W.T.; Kraaijeveld, K.; Snippe, H. Th1-directing adjuvants increase the immunogenicity of oligosaccharide-protein conjugate vaccines related to Streptococcus pneumoniae type 3. Infect. Immun. 2003, 71, 6915-6920. [CrossRef] [PubMed]

39. Mountford, A.P.; Fisher, A.; Wilson, R.A. The profile of IgG1 and IgG2a antibody responses in mice exposed to Schistosoma mansoni. Parasite Immunol. 1994, 16, 521-527. [CrossRef] [PubMed]

40. Berarducci, B.; Ikoma, M.; Stamatis, S.; Sommer, M.; Grose, C.; Arvin, A.M. Essential functions of the unique N-terminal region of the varicella-zoster virus glycoprotein E ectodomain in viral replication and in the pathogenesis of skin infection. J. Virol. 2006, 80, 9481-9496. [CrossRef]

41. Malavige, G.N.; Jones, L.; Black, A.P.; Ogg, G.S. Varicella zoster virus glycoprotein E-specific CD4+ T cells show evidence of recent activation and effector differentiation, consistent with frequent exposure to replicative cycle antigens in healthy immune donors. Clin. Exp. Immunol. 2008, 152, 522-531. [CrossRef]

42. Moffat, J.; Mo, C.; Cheng, J.J.; Sommer, M.; Zerboni, L.; Stamatis, S.; Arvin, A.M. Functions of the C-terminal domain of varicella-zoster virus glycoprotein E in viral replication in vitro and skin and T-cell tropism in vivo. J. Virol. 2004, 78, 12406-12415. [CrossRef]

43. Garcia-Valcarcel, M.; Fowler, W.J.; Harper, D.R.; Jeffries, D.J.; Layton, G.T. Induction of neutralizing antibody and T-cell responses to varicella-zoster virus (VZV) using Ty-virus-like particles carrying fragments of glycoprotein E (gE). Vaccine 1997, 15, 709-719. [CrossRef]

44. Zhu, R.; Liu, J.; Chen, C.; Ye, X.; Xu, L.; Wang, W.; Zhao, Q.; Zhu, H.; Cheng, T.; Xia, N. A highly conserved epitope-vaccine candidate against varicella-zoster virus induces neutralizing antibodies in mice. Vaccine 2016, 34, 1589-1596. [CrossRef]

45. Upadhyay, S.; Jeena, G.S.; Shikha; Shukla, R.K. Recent advances in steroidal saponins biosynthesis and in vitro production. Planta 2018, 248, 519-544. [CrossRef] 
46. Dendouga, N.; Fochesato, M.; Lockman, L.; Mossman, S.; Giannini, S.L. Cell-mediated immune responses to a varicella-zoster virus glycoprotein E vaccine using both a TLR agonist and QS21 in mice. Vaccine 2012, 30, 3126-3135. [CrossRef] [PubMed]

47. Wui, S.R.; Kim, K.S.; Ryu, J.I.; Ko, A.; Do, H.T.T.; Lee, Y.J.; Kim, H.J.; Lim, S.J.; Park, S.A.; Cho, Y.J.; et al. Efficient induction of cell-mediated immunity to varicella-zoster virus glycoprotein E co-lyophilized with a cationic liposome-based adjuvant in mice. Vaccine 2019, 37, 2131-2141. [CrossRef] [PubMed]

48. Meyer, C.; Engelmann, F.; Arnold, N.; Krah, D.L.; ter Meulen, J.; Haberthur, K.; Dewane, J.; Messaoudi, I. Abortive intrabronchial infection of rhesus macaques with varicella-zoster virus provides partial protection against simian varicella virus challenge. $J$. Virol. 2015, 89, 1781-1793. [CrossRef] [PubMed]

49. Wroblewska, Z.; Valyi-Nagy, T.; Otte, J.; Dillner, A.; Jackson, A.; Sole, D.P.; Fraser, N.W. A mouse model for varicella-zoster virus latency. Microb. Pathog. 1993, 15, 141-151. [CrossRef]

50. Maurer, T.; Heit, A.; Hochrein, H.; Ampenberger, F.; O’Keeffe, M.; Bauer, S.; Lipford, G.B.; Vabulas, R.M.; Wagner, H. CpG-DNA aided cross-presentation of soluble antigens by dendritic cells. Eur. J. Immunol. 2002, 32, 2356-2364. [CrossRef]

51. Bode, C.; Zhao, G.; Steinhagen, F.; Kinjo, T.; Klinman, D.M. CpG DNA as a vaccine adjuvant. Expert Rev. Vaccines 2011, 10, 499-511. [CrossRef] [PubMed]

52. Kalimuddin, S.; Wijaya, L.; Chan, Y.F.Z.; Wong, A.W.L.; Oh, H.M.L.; Wang, L.F.; Kassim, J.A.; Zhao, J.; Shi, Z.; Low, J.G. A phase II randomized study to determine the safety and immunogenicity of the novel PIKA rabies vaccine containing the PIKA adjuvant using an accelerated regimen. Vaccine 2017, 35, 7127-7132. [CrossRef] [PubMed]

53. Heyward, W.L.; Kyle, M.; Blumenau, J.; Davis, M.; Reisinger, K.; Kabongo, M.L.; Bennett, S.; Janssen, R.S.; Namini, H.; Martin, J.T. Immunogenicity and safety of an investigational hepatitis B vaccine with a Toll-like receptor 9 agonist adjuvant (HBsAg-1018) compared to a licensed hepatitis B vaccine in healthy adults 40-70 years of age. Vaccine 2013, 31, 5300-5305. [CrossRef] [PubMed]

54. Ball, R.L.; Bajaj, P.; Whitehead, K.A. Achieving long-term stability of lipid nanoparticles: Examining the effect of $\mathrm{pH}$, temperature, and lyophilization. Int. J. Nanomed. 2017, 12, 305-315. [CrossRef] 